\title{
Cholangiocarcinoma following external beam radiotherapy: A report of two cases
}

\author{
ANISHA KULKARNI ${ }^{1}$, JUSTIN S. GUNDARA ${ }^{1}$, ANTHONY J. GILL ${ }^{2}$, \\ THOMAS J. HUGH ${ }^{1}$ and JASWINDER S. SAMRA ${ }^{1}$ \\ ${ }^{1}$ Upper Gastrointestinal Surgical Unit; ${ }^{2}$ Department of Anatomical Pathology, Royal North Shore Hospital, \\ University of Sydney, St. Leonards, Sydney, NSW 2065, Australia
}

Received December 9, 2014; Accepted November 13, 2015

DOI: $10.3892 / \mathrm{ol} .2017 .6113$

\begin{abstract}
Cholangiocarcinoma (CCA) is a relatively rare primary malignancy, with established risk factors that include primary sclerosing cholangitis, choledochal cysts and hepatolithiasis. In the present study, two cases of CCA, which occurred following abdominal external beam radiotherapy (EBRT) for non-Hodgkin's lymphoma, are reported. Case 1 and 2 were diagnosed with cholangiocarcinoma 30 and 4 years following treatment with combined chemotherapy and abdominal radiotherapy treatment, respectively. The patients received chemotherapy as treatment of cholangiocarcinoma; however, whilst their symptoms improved, they succumbed within 12 and 2 months respectively following the diagnosis with cholangiocarcinoma. Currently, the association between radiation exposure and hepatobiliary malignancy remains unclear, however, we hypothesize that biliary epithelium sensitivity to ionizing radiation may have contributed to the etiology of the secondary malignancies observed in these two patients. This study indicates that patients treated with abdominal EBRT may benefit from a heightened index of suspicion and more intensive surveillance for secondary biliary malignancies.
\end{abstract}

\section{Introduction}

Cholangiocarcinoma (CCA) is a relatively rare hepatobiliary malignancy, with an incidence of $<1$ case per 100,000 individuals, which accounts for $3 \%$ of all gastrointestinal malignancies worldwide $(1,2)$. Known risk factors for the development of CCA include primary sclerosing cholangitis, choledochal cysts and hepatolithiasis, as well as liver flukes in Asian populations (2).

Patients with extra-hepatic cholangiocarcinoma often present with symptoms of biliary obstruction, including

Correspondence to: Dr Anisha Kulkarni, Upper Gastrointestinal Surgical Unit, Royal North Shore Hospital, University of Sydney, Reserve Road, St. Leonards, Sydney, NSW 2065, Australia

E-mail: anisha.kulkarni@gmail.com

Key words: cholangiocarcinoma, radiotherapy, lymphoma painless jaundice, pale stools, dark urine and pruritis. Intra-hepatic disease may present differently, often with less specific symptoms, such as malaise, abdominal pain and weight loss (3).

Commonly used diagnostic imaging modalities for CCA include computed tomography (CT) and magnetic resonance cholangio-pancreatography. Endoscopic ultrasound and endoscopic retrograde cholangio-pancreatography are useful for imaging distal extra-hepatic lesions, as these techniques allow stenting to relieve biliary obstruction and cytological brushings to be obtained $(3,4)$. Diagnosis may also be supported by elevated levels of the tumor marker, carcinoembryonic antigen 19-9 (4).

Surgical resection remains the standard treatment for cholangiocarcinoma, however 5-year postoperative survival rates remain poor at $27-37 \%$ for patients with extra-hepatic disease and $23-42 \%$ for patients with intra-hepatic disease and clear surgical margins $(3,4)$.

In the current study, two cases of CCA, in patients who had previously undergone external beam radiotherapy (EBRT) for the treatment of non-Hodgkin's lymphoma (NHL), are presented. The clinical data of the patients are presented and the medical records of the patients are retrospectively reviewed. The study details the clinical history, investigations and outcome of these two cases of this rarely encountered phenomenon, which may ultimately be considered an unusual but important variant of CCA. We hypothesize that the biliary epithelium is particularly sensitive to EBRT and review the current literature to investigate the proposed etiology of secondary malignancies following EBRT.

\section{Case report}

Case 1. In August 1981, a 10-year-old female was diagnosed with metastatic abdominal NHL [Ann Arbor stage IV (5)], after presenting to Westmead Children's Hospital (Sydney, Australia) with massive hepatosplenomegaly. The patient was administered combined chemotherapy and radiotherapy with the LSA2L2 (6) protocol for 3 years, and received prophylactic cranial (24 Gy) and abdominal (7.2 Gy) irradiation for residual lymphoma. Abdominal irradiation was terminated early due to marrow suppression. The patient was well when discharged 
and was followed up in the hospital's Late-Effects Clinic for 22 years.

In July 2011, the patient presented with symptomatic cholelithiasis, and underwent an uncomplicated laparoscopic cholecystectomy (normal cholangiogram). However, at 2 months post-surgery, the patient presented with painless, obstructive jaundice. Endoscopic retrograde cholangiopancreatography (ERCP) proved technically difficult and following two failed attempts, a biliary stricture was identified. The stricture was subsequently dilated and stented using an antegrade, percutaneous transhepatic (PTC) approach (Fig. 1). The stricture was located $1 \mathrm{~cm}$ proximal to the common hepatic duct and $1 \mathrm{~cm}$ into the common bile duct. During follow-up ERCP, progression of the stricture was identified and a new plastic stent was inserted. No evidence of malignancy was identified on radiological or biochemical examination and thus, a benign bile duct stricture was presumptively diagnosed and the patient was referred for hepatico-jejunostomy.

During the hepatico-jejunostomy, widespread omental and abdominal metastatic disease was identified and thus, surgery was abandoned. Histopathological examination of the peritoneal biopsy demonstrated adenocarcinoma of pancreaticobiliary origin with a typical morphology and immunohistochemical profile [cytokeratin $(\mathrm{CK}) 7^{+}, \mathrm{CK} 20^{-}$. Subsequent positron emission tomography (PET) scans showed uptake surrounding the biliary stent, and CCA was diagnosed.

The patient was administered 3 cycles (21 days/cycle) of combined chemotherapy with cisplatin and gemcitabine, which was changed to paclitaxel when disease progression was observed. A further PTC and ERCP with a metal stent were required to relieve the common bile duct obstruction. The patient was discharged to a palliative care unit and succumbed to the disease at 41 years of age, 31 years after the diagnosis of NHL and the delivery of EBRT, and 12 months after the diagnosis of CCA.

Case 2. In May 1997, a 42-year-old male was diagnosed with stage IVB NHL (5) following an inguinal node biopsy for a suspicious groin lymphadenopathy at Royal North Shore Hospital (Sydney, Australia). The patient subsequently underwent six cycles (21 days/cycle) of cyclophosphamide, hydroxydaunorubicin, vincristine and prednisone (CHOP) chemotherapy, achieving complete remission for 8 years. At this time in July 2005, the patient relapsed with widespread lymphadenopathy and was administered six further cycles of CHOP chemotherapy, achieving remission for another 3 years. The patient relapsed again 3 years later in May 2008, presenting with abdominal, back and flank pain. A PET scan revealed uptake in the left upper abdomen and para-aortic nodes. Four cycles (21 days/cycle) of rituximab, ifosfamide, carboplatin and etoposide salvage chemotherapy were subsequently administered and an autologous stem cell transplant was performed the following year. The transplant was followed by abdominal EBRT to the left upper mesenteric mass; a total of $38 \mathrm{~Gy}$ of radiation was delivered.

The patient was presented to the Upper Gastrointestinal Service 4 years later, in June 2012 with painless obstructive jaundice. Blood tests revealed a bilirubin level of $300 \mu \mathrm{mol} / 1$ (normal range, 3-20 $\mu \mathrm{mol} / \mathrm{l}$ ) and a carcinoembryonic

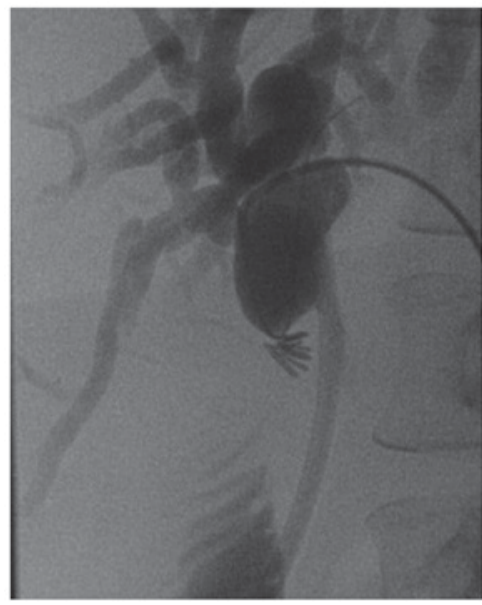

Figure 1. Case 1: Intraoperative cholangiogram image. Stenting of the biliary stricture performed using an antegrade percutaneous transhepatic approach.

antigen 19-9 level of 15,120 U/ml (normal range, $<37 \mathrm{U} / \mathrm{ml}$ ). A CT scan revealed mid-common bile duct obstruction. An ERCP with stenting was performed and cytology confirmed the diagnosis of CCA due to the presence of adenocarinoma on histological staining samples from the common bile duct. A staging laparoscopy revealed widespread metastatic disease. The patient was subsequently transferred to a palliative care facility in Sydney, Australia and succumbed to the disease at 58 years of age, 16 years after the initial diagnosis of NHL, 4 years after the administration of EBRT and 2 months after the diagnosis of CCA.

Written informed consent was obtained from the families of each patient for publication of the study data.

\section{Discussion}

Modern cancer therapies have led to increases in the quality of life and prognosis of cancer patients, allowing for the observation of long-term sequelae of cancer therapies. The risk of secondary malignancies following delivery of EBRT has been identified previously in a number of studies (7-10). Known risk factors for this include a younger age at diagnosis, high radiation dose and being of the female gender (11).

In 1948, Cahan and Woodard (12) proposed certain classic criteria that were required for the diagnosis of secondary malignancies due to prior radiotherapy treatment. These criteria remain widely accepted as a conservative guide and stipulate that affected patients must possess the following: i) A prior history of radiation treatment; ii) an asymptomatic latent period of several years; iii) occurrence of a second malignancy within the previously irradiated field; and iv) histopathology of a secondary malignancy distinct from that of the primary malignancy (12).

Primary cancers that have been consistently associated with a high risk of EBRT-associated secondary malignant neoplasm (SMN), include breast cancer, prostate cancer and lymphoma (including Hodgkin's and non-Hodgkin's subtypes) (11). The most commonly described SMNs vary with regard to primary cancer site and radiation field. In patients treated for NHL, the most common SMNs include leukaemia 
and lung cancer $(7-9,13)$ as well as melanoma in Australian populations (14).

At present, the association between ionizing radiation exposure and hepatobiliary malignancy remains unclear. Recently, Dores et al (15) reported an increased risk of pancreatic malignancy in patients treated with moderate to high doses of EBRT for Hodgkin's lymphoma. Furthermore, the study demonstrated that this risk was higher in patients treated with both EBRT and chemotherapy, which indicates a possible interaction between the two treatment modalities in contributing to SMN. Similarly, Morton et al (16) reported an increased risk of stomach cancer with EBRT, and showed that this risk was associated with the sub-diaphragmatic radiation dose.

Radiation exposure associated with hepatobiliary malignancy has previously been reported within the context of Thorotrast $(17,18)$ and in survivors of atomic bomb fallout exposure in Nagasaki and Hiroshima $(19,20)$.

In total, 5 cases of EBRT-associated CCA have been previously reported in the literature; 3 of these cases occurred 18-23 years after EBRT for urogenital carcinoma (21), and two cases occurred following abdominal EBRT for Hodgkin's lymphoma and teratocarcinoma, respectively (22). Radiation-induced liver disease is a known complication of EBRT (23), and there have also been reports of patients developing hepatocellular carcinoma (24) and benign biliary strictures $(25,26)$ following EBRT.

The molecular mechanism of EBRT-induced biliary carcinogenesis remains unclear. However, it has been postulated that chronic inflammation secondary to biliary epithelial injury, and the accompanying disruption to bile flow, are important factors in the development of carcinogenesis (27-29). Persistent inflammation is hypothesized to damage DNA mismatch repair genes and tumor suppressor genes, thus promoting carcinogenesis (27). Cheng et al (23) previously suggested that hepatocytes may be more susceptible to radiation injury than the biliary epithelium, however, the susceptibility of these cell-types to radiation has not yet been reported.

In the present study, in the two cases reported, the histopathology was consistent with primary CCA. Considering the reported occurrence of CCA and other hepatobiliary complications (21-26,30,31), we hypothesize that chronic inflammatory reactions and resultant changes to the biliary epithelium following abdominal EBRT were fundamental to the development of CCA. However, it is unclear whether this represents a radiation-associated variant of the disease.

CCA continues to exhibit a poor prognosis. Thus, risk factors must be closely assessed to improve patient prognosis. Abdominal EBRT must be recognized as a risk factor of SMNs and thus, a heightened index of suspicion and more intensive surveillance of patients may facilitate an earlier diagnosis.

\section{References}

1. Gatto M, Bragazzi MC, Semeraro R, Napoli C, Gentile R, Torrice A, Gaudio E and Alvaro D: Cholangiocarcinoma: Update and future perspectives. Dig Liver Dis 42: 253-260, 2010.

2. Tyson GL and El-Serag HB: Risk factors for cholangiocarcinoma. Hepatology 54: 173-184, 2011.

3. Van Beers BE: Diagnosis of cholangiocarcinoma. HPB (Oxford) 10: 87-93, 2008.
4. Ghouri YA, Mian I and Blechacz B: Cancer review: Cholangiocarcinoma. J Carcinog 14: 1, 2015.

5. Carbone PP, Kaplan HS, Musshoff K, Smithers DW and Tubiana M: Report of the Committee on Hodgkin's Disease Staging Classification. Cancer Res 31: 1860-1861, 1971.

6. Wollner N, Burchenal JH, Lieberman PH, Exelby P, D'Angio G and Murphy ML: Non-Hodgkin's lymphoma in children. A comparative study of two modalities of therapy. Cancer 37: 123-134, 1976.

7. Sacchi S, Marcheselli L, Bari A, Marcheselli R, Pozzi S, Luminari S, Lombardo M, Buda G, Lazzaro A, Gobbi PG, et al: Secondary malignancies after treatment for indolent non-Hodgkin's lymphoma: A 16-year follow-up study. Haematologica 93: 398-404, 2008

8. Travis LB, Curtis RE, Boice JD Jr, Hankey BF and Fraumeni JF Jr: Second cancers following non-Hodgkin's lymphoma. Cancer 67: 2002-2009, 1991

9. Travis LB, Curtis RE, Glimelius B, Holowaty E, Van Leeuwen FE, Lynch CF, Adami J, Gospodarowicz M, Wacholder S and Inskip P: Second cancers among long-term survivors of non-Hodgkin's lymphoma. J Natl Cancer Inst 85: 1932-1937, 1993.

10. Xu XG, Bednarz B and Paganetti H: A review of dosimetry studies on external-beam radiation treatment with respect to second cancer induction. Phys Med Biol 53: R193-R241, 2008.

11. Tubiana M: Can we reduce the incidence of second primary malignancies occurring after radiotherapy? A critical review. Radiother Oncol 91: 4-15, 2009.

12. Cahan WG and Woodard HQ: Sarcoma arising in irradiated bone; report of eleven cases. Cancer 1: 3-29, 1948.

13. Mudie NY, Swerdlow AJ, Higgins CD, Smith P, Qiao Z, Hancock BW, Hoskin PJ and Linch DC: Risk of second malignancy after non-Hodgkin's lymphoma: A British cohort study. J Clin Oncol 24: 1568-1574, 2006.

14. Brennan P, Coates M, Armstrong B, Colin D and Boffetta P: Second primary neoplasms following non-Hodgkin's lymphoma in New South Wales, Australia. Br J Cancer 82: 1344-1347, 2000.

15. Dores GM, Curtis RE, van Leeuwen FE, Stovall M, Hall P, Lynch CF, Smith SA, Weathers RE, Storm HH, Hodgson DC, et al: Pancreatic cancer risk after treatment of Hodgkin lymphoma. Ann Oncol 25: 2073-2079, 2014.

16. Morton LM, Dores GM, Curtis RE, Lynch CF, Stovall M, Hall P, Gilbert ES, Hodgson DC, Storm HH, Johannesen TB, et al: Stomach cancer risk after treatment for hodgkin lymphoma. J Clin Oncol 31: 3369-3377, 2013.

17. Andersson M and Storm HH: Cancer incidence among Danish Thorotrast-exposed patients. J Natl Cancer Inst 84: 1318-1325, 1992.

18. van Kaick G, Dalheimer A, Hornik S, Kaul A, Liebermann D, Lührs H, Spiethoff A, Wegener K and Wesch H: The german thorotrast study: Recent results and assessment of risks. Radiat Res 152: S64-S71, 1999.

19. Cologne JB, Tokuoka S, Beebe GW, Fukuhara T and Mabuchi K: Effects of radiation on incidence of primary liver cancer among atomic bomb survivors. Radiat Res 152: 364-373, 1999.

20. Preston DL, Ron E, Tokuoka S, Funamoto S, Nishi N, Soda M, Mabuchi K and Kodama K: Solid cancer incidence in atomic bomb survivors: 1958-1998. Radiat Res 168: 1-64, 2007.

21. Biermann CW, Fröschle G, Kuhlencordt R, Schwarz R and Gonnermann D: Bile duct carcinoma after abdominal irradiation for urologic malignancies. Helv Chir Acta 60: 1131-1136, 1994 (In German).

22. Burmeister BH and Turner SL: External beam radiation therapy as an agent in the aetiology of carcinoma of the bile duct: A report on two patients. Clin Oncol (R Coll Radiol) 7: 48-49, 1995.

23. Cheng JC, Wu JK, Huang CM, Huang DY, Cheng SH, Lin YM, Jian JJ, Yang PS, Chuang VP and Huang AT: Radiation-induced liver disease after radiotherapy for hepatocellular carcinoma: Clinical manifestation and dosimetric description. Radiother Oncol 63: 41-45, 2002.

24. Greten TF, Manns MP, Reinisch I and Kaatsch P: Hepatocellular carcinoma occurring after successful treatment of childhood cancer with high dose chemotherapy and radiation. Gut 54: 732, 2005.

25. Cherqui D, Palazzo L, Piedbois P, Charlotte F, Duvoux C, Duron JJ, Fagniez PL and Valla D: Common bile duct stricture as a late complication of upper abdominal radiotherapy. J Hepatol 20: 693-697, 1994. 
26. Nakakubo Y, Kondo S, Katoh $\mathrm{H}$ and Shimizu M: Biliary stricture as a possible late complication of radiation therapy Hepatogastroenterology 47: 1531-1532, 2000.

27. Jaiswal M, LaRusso NF, Burgart LJ and Gores GJ: Inflammatory cytokines induce DNA damage and inhibit DNA repair in cholangiocarcinoma cells by a nitric oxide-dependent mechanism. Cancer Res 60: 184-190, 2000.

28. Schottenfeld D and Beebe-Dimmer J: Chronic inflammation: A common and important factor in the pathogenesis of neoplasia. CA Cancer J Clin 56: 69-83, 2006.
29. Wise C, Pilanthananond M, Perry BF, Alpini G, McNeal M and Glaser SS: Mechanisms of biliary carcinogenesis and growth. World J Gastroenterol 14: 2986-2989, 2008.

30. Gorea G, Demy M, Tran Van Nhieu J, Tigori J, Aubé C, Cherqui D, Oberti F, Caroli-Bosc FX and Calès P: Radiation-induced cholangitis with hepatocellular Carcinoma. Gastroenterol Clin Biol 34: 35-39, 2010.

31. Lawrence TS, Robertson JM, Anscher MS, Jirtle RL, Ensminger WD and Fajardo LF: Hepatic toxicity resulting from cancer treatment. Int J Radiat Oncol Biol Phys 31: 1237-1248, 1995. 